\title{
STRATEGI PENGEMBANGAN SENTRA PERIKANAN PERAIRAN UMUM DARATAN SEBAGAI KAWASAN MINAPOLITAN
}

\author{
Muhadjir dan Zahri Nasution \\ Balai Besar Penelitian Sosial Ekonomi Kelautan dan Perikanan \\ JI. KS. Tubun Petamburan VI Jakarta 10260 \\ Telp. (021) 53650162, Fax. (021)53650159 \\ E-mail: muhadjir_nasir@yahoo.com
}

Diterima 8 Mei 2012 - Disetujui 20 Juni 2012

\begin{abstract}
ABSTRAK
Kajian ini bertujuan untuk mengetahui kesiapan per aspek maupun secara keseluruhan aspek serta strategi yang dapat dikembangkan dalam mendukung sentra perikanan perairan umum daratan (PUD) sebagai kawasan minapolitan. Pendekatan penelitian yang digunakan adalah studi kasus pada 9 (Sembilan) kabupaten yang berpotensi untuk dikembangkan sebagai kawasan minapolitan. Teknik pengumpulan data yaitu melalui studi pustaka, wawancara, Rapid Rural Appraisal (RRA) dan mail survey. Kajian ini menggunakan metode analisis SWOT (Strength, Weakness, Opportunity and Threat) untuk merumuskan strategi pengembangan kawasan minapolitan. Hasil penelitian ini adalah berupa rumusan strategi pengembangan kawasan minapolitan pada 4 (empat) ekosistem PUD yaitu waduk, sungai/rawa, sungai dan danau. Strategi pengembangan kawasan minapolitan untuk pada ekosistem waduk (Jatiluhur, Kabupaten Purwakarta, Jawa Barat) terkait dengan pengelolaan keberlanjutan sumber daya waduk (pengawasan dan pembatasan KJA). Pada ekosistem sungai/rawa (Kabupaten Ogan Ilir, Kabupaten Sumatera Selatan) strategi pengembangannya terkait dengan pemanfaatan sumber daya air sebagai saran transportasi maupun kegiatan perikanan. Pada ekosistem sungai (Kabupaten Barito Selatan, Kalimantan Tengah) strategi pengembangan minapolitan yang perlu dilakukan terkait dengan pembangunan infrastruktur pendukung baik dari sisi transportasi dan pemasaran hasil produksi perikanan. Pada ekosistem danau (Toba, Kabupaten

Simalungun, Sumatera Utara) strategi yang perlu dilakukan terkait dengan perumusan kebijakan-kebijakan mengenai pengelolaan danau seperti pengawasan dan pengendalian penggunaan alat tangkap.
\end{abstract}

Kata Kunci: sosial ekonomi, strategi pengembangan, perairan umum daratan, minapolitan

\section{Abstract: Economic and Social Characteristics and Development Strategy Inland Fisheries as Minapolitan Development Area. By: Muhadjir and Zahri Nasution.}

This study aims to determine the readiness per aspect and overall aspects and strategies that can be developed in support the inland waters fisheries centers (PUD) as minapolitan area. The research approach was using a case study on a 9 (nine) districts that have the potential to be developed as the minapolitan. The data collection techniques were through literature study, interviews, Rapid Rural Appraisal (RRA) and mail surveys.The research was using the method of SWOT analysis (Strength, Weakness, Opportunity and Threat) to formulate development strategies of minapolitan area. The results of this study were the development strategy formulation of minapolitan area in 4 (four) PUD ecosystems, namely reservoirs, rivers / swamps, rivers and lakes. Development strategy of Minapolitan area for the reservoir ecosystem (Jatiluhur, Purwakarta Regency, West Java) related to sustainable management of reservoir resources (supervision and restriction KJA). On the river ecosystem / swamp (Ogan Ilir, South Sumatra Regency) the development strategy related to the use of water resources for transportation and fisheries activities. On the river ecosystem (South Barito Regency, Central Kalimantan) Minapolitan development strategy needs to be done related to the development of supporting infrastructure in terms of transportation and marketing 
of fishery products. In the ecosystem of the lake (Toba, Simalungun District, North Sumatra) strategies need to be linked to the formulation of policies concerning the management of the lake such as monitoring and controlling of fishing gears.

Keywords: social economics, development strategy, inland waters, minapolitan

\section{PENDAHULUAN}

Sejak digulirkannya program peningkatan produksi perikanan Nasional sesuai Rencana Strategis (Renstra) Kementerian Kelautan dan Perikanan (KKP), peranan perikanan perairan umum daratan diharapkan dapat memberikan sumbangan dan pencapaian peningkatan produksi perikanan. Langkah-langkah yang diambil adalah ditetapkannya beberapa pengembangan minapolitan yang berbasis pada sumberdaya perikanan perairan umum daratan (PUD). Namun demikian, pemanfaatan dan pengelolaan sumberdaya perikanan perairan umum seyogyanya berdasarkan atas prinsip-prinsip pembangunan berkelanjutan (sustainable development). Menurut UU No. 31 tahun 2004 tentang perikanan, pengelolaan perikanan dilakukan berdasarkan pada azas manfaat, keadilan, kemitraan, pemerataan, keterpaduan, efisiensi, dan kelestarian yang berkepanjangan. Dalam prinsip ini, pemanfaatan dan pengelolaan sumberdaya perikanan perairan umum harus mempertimbangkan beberapa aspek penting; yaitu aspek ekologi, sosial, dan ekonomi.

Dari aspek ekologi, pemanfaatannya harus menggunakan teknologi yang bersifat ramah lingkungan, sementara dari aspek ekonomi, pemanfaatan sumberdaya perikanan tersebut menghasilkan nilai ekonomi terhadap pengguna. Kemudian, dari aspek sosial, pemanfaatan dan pengelolaan yang dilakukan terhadap sumberdaya perikanan perairan umum tersebut dapat diterima masyarakat yang berkepentingan (pemangku kepentingan; stakeholders). Ketiga aspek yang dikemukakan di atas terbentuk dalam suatu kerangka peraturan pemanfaatan dan pengelolaan sumberdaya perikanan perairan umum yaitu dalam suatu kelembagaan. Adrianto, (2011) mengemukakan bahwa dalam sejarahnya, pengelolaan perikanan di Indonesia sesungguhnya dimulai dengan inisiatif yang muncul dari masyarakat lokal dengan menggunakan pemahaman yang mereka punya (pengetahuan lokal/local knowledge, customary knowledge), kemudian dilembagakan dengan menggunakan system hukum adat (customary laws). Dengan berkembangnya waktu, praktek ini semakin tereduksi oleh rezim pengelolaan yang kemudian lebih didominasi oleh pemerintah, khususnya pada era tahun 1966-1998.

Terkait dengan konsep pembangunan ekonomi terhadap wilayah tertentu, maka muncul gagasan pembangunan kawasan minapolitan. Dalam hal ini, konsep Minapolitan merupakan salah satu konsep utama yang digunakan Kementerian Kelautan dan Perikanan (KKP) dalam menjalankan pembangunan kelautan dan perikanan, setidaknya hingga tahun 2014. Hal ini, akan berkaitan penting dalam perumusan model pembangunan ekonomi masyarakat di wilayah tertentu (minapolitan) dengan mengandalkan sumberdaya perikanan perairan umum. Untuk itu, karakteristik sosial ekonomi dalam kerangka pengembangan model minapolitan berbasis perikanan perairan umum daratan menjadi penting dipetakan untuk menunjang suksesnya program tersebut.

Beberapa aspek yang harus dipertimbangkan dalam upaya peningkatan produksi perikanan perairan umum adalah aspek sumberdaya dan tata ruang. Pengembangan produksi perikanan perairan umum tersebut tidak akan optimal jika tidak 
terintegrasi dengan aspek-aspek lainnya seperti aspek masyarakat dan bisnis, aspek kelembagaan, keberadaan infrastruktur serta dukungan kebijakan dan governance. Keterkaitan antar aspek-aspek tersebut pada dasarnya adalah penerapan prinsip prinsip ko-manajemen dimana pengelolaan perikanan tidak dapat terlepas dari peran banyak pihak seperti: nelayan, pemerintah, lembaga/ institusi non pemerintah, akademisi, pelaku perikanan lainnya seperti pedagang, kelompok pengelola ikan, dan lain lain (Adrianto, 2011). Ko-manajemen didefinisikan sebagai berbagi peran dan tanggung jawab atau kewenangan diantara pemerintah dan pemanfaat lokal sumberdaya untuk mengelola suatu badan air atau sumberdaya tertentu, misalnya sumberdaya perikanan, sumberdaya pesisir, sumberdaya air (ICLARM and IFM, 1996 dalam Kartamihardja et al., 2008). Prinsip ko-manajemen menuntut adanya sinergitas antar pihak agar pengelolaan sumberdaya perikanan dapat berhasil. Berkaitan dengan pelaksanaan ko-manajemen ini, Kartamihardja et al., (2008) mengemukakan 3 (tiga) tipe ko-manajemen meliputi: (1) Ko-manajemen konsultatif (consultative ko-management), dalam hal ini pemerintah berkonsultasi dengan kelompok pemanfaat tetapi keputusan diambil oleh pemerintah; (2) Ko-manajemen kooperatif (cooperative ko-management), dalam hal ini pemerintah dan kelompok pemanfaat bekerjasama pada tingkatan yang sama dalam pembuatan keputusan; dan (3) Ko-manajemen yang didelegasikan (delegated ko-management), dalam hal ini kelompok pemanfaat mempunyai kewenangan pengelolaan dan keputusan yang diambilnya diinformasikan ke pemerintah. Sejalan dengan itu, kegagalan pembangunan juga sering disebabkan oleh adanya kesenjangan fokus pengembangan antara kota dan desa, kemiskinan yang lebih besar di kawasan perdesaan, dan fenomena urbanisasi. Dalam hal pengelolaan perikanan perairan umum daratan ini, Hartoto (2009) dengan memodifikasi dari FAO (1997) mengemukakan 15 azas pengelolaan meliputi: (1) azas kewajiban dan partisipasi sebagai pengguna dalam sistem multiguna, (2) azas pembangunan berkelanjutan, (3) azas penyesuaian antara kapasitas alam dan kapasitas produksi manusia, (4) azas pemanfaatan bukti ilmiah terbaik, (5) azas pendekatan kehati hatian dalam pengelolaan perikanan, (6) azas optimasi dan keamanan alat penangkapan, (7) azas penghormatan pada nilai etik hasil tangkapan dan sumberdaya alam, (8) azas perlindungan terhadap habitat penting dalam daur hidup ikan, (9) azas pertimbangan terhadap sifat multiguna kawasan pesisir, (10) azas penegakan peraturan konservasi lintas daerah, (11) azas kewajiban kerjasama antara daerah dalam pengelolaan produksi dan konservasi, (12) azas transparansi dalam proses pengambilan keputusan, (13) azas kewajiban pemerintah sebagai badan arbitrase perselisihan; (14) azas kewajiban melaksanakan pelatihan tentang sendi sendi perikanan yang bertanggung jawab, dan (15) azas pemaduan potensi akuakultur untuk penganekaragaman produk perikanan tangkap. Dalam kaitan inilah, pengembangan kawasan minapolitan berbasis sumberdaya perikanan perairan umum daratan merupakan alternatif pembangunan kawasan perdesaan perikanan umum daratan. Tulisan ini bertujuan mengemukakan prioritas lokasi sentra produksi perikanan perairan umum daratan sebagai kawasan minapolitan serta rumusan strategi pengembangan kawasan minapolitan perairan umum daratan tersebut.

\section{METODOLOGI}

\section{Kerangka Pemikiran dan Pendekatan Analisis}

Variabel sosial ekonomi terkait dengan kawasan minapolitan dirumuskan berdasarkan pada aspek-aspek generik yang terdapat dalam model minapolitan. Variabel sosial ekonomi ini dijadikan dasar dalam menentukan aktivitas perekonomian, keunggulan kawasan minapolitan, serta perumusan kebijakan/ strategi pengembangan kawasan minapolitan. Aspek generik yang dihasilkan dalam workshop minapolitan untuk merumuskan model minapolitan telah dilakukan oleh BBPSEKP pada tahun 2010 (Zulham dan Purnomo, 
2010). Aspek generik tersebut juga menjadi rumusan model minapolitan berbasis sumber daya perikanan perairan umum daratan. Aspek-aspek generik tersebut adalah sebagai berikut: 1) Aspek sumber daya dan tata ruang; 2) Aspek masyarakat dan bisnis; 3) Aspek kelembagaan; 4) Aspek infrastruktur; 5) Aspek kebijakan dan governance; 6) Aspek teknologi; dan 7) Aspek pemasaran hasil perikanan.

Aspek-aspek generik tersebut di atas dapat dijabarkan menjadi beberapa variabel sosial ekonomi yang selanjutnya merupakan sekelompok variabel yang menjadi halhal yang diperlukan dalam merumuskan strategi pengembangan kawasan minapolitan perairan umum daratan. Pada saat yang sama juga dilakukan analisis terhadap perekonomian wilayah atau kawasan yang diteliti sebagai kawasan minapolitan, termasuk menentukan faktor unggulan yang terdapat dalam kawasan minapolitan tersebut.

\section{Waktu dan Lokasi Penelitian}

Penelitian ini dilakukan tahun 2011. Lokasi kegiatan adalah lokasi sentra kegiatan perikanan perairan umum di beberapa kabupaten terpilih yang dominan memiliki sumber daya dan usaha perikanan perairan umum daratan. Kawasan ini merupakan kawasan yang berpotensi dikembangkan sebagai kawasan minapolitan sesuai dengan tipologi sumber daya perikanan perairan umum daratan, termasuk kawasan yang ditetapkan oleh Kementerian Kelautan dan Perikanan melalui Direktorat Usaha Penangkapan Ikan, Direktorat Jenderal Perikanan Tangkap (DJPT).

Lokasi penelitian adalah lokasi minapolitan perairan umum daratan yang telah ditetapkan oleh DJPT pada tahun 2011 yaitu: perairan sungai dan rawa di Kab. Ogan Ilir (Sumatera Selatan), perairan danau di Kab. Kerinci (Jambi), dan perairan danau di Kab. Simalungun (Sumatera Utara). Di samping itu, lokasi penelitian lainnya adalah lokasi yang merupakan sentra produksi perikanan perairan umum daratan dari berbagai ekosistem yaitu: perairan umum sungai dan rawa di Kab. Barito Selatan (Kalimantan Tengah), Kab. Musi Banyuasin (Sumatera Selatan), dan Kab. Hulu Sungai Utara (Kalimantan Selatan); perairan umum waduk di Kab. Purwakarta (Jawa Barat), dan Kab. Wonogiri (Jawa Tengah); serta perairan umum danau di Kab. Agam (Sumatera Barat). Cakupan kawasan penelitian dapat saja meliputi wilayah administrasi pemerintahan yang terdiri dari satu atau beberapa desa dalam satu atau berbeda kecamatan/kabupaten/kota. Desa-desa tersebut harus termasuk dalam kriteria desa yang marketable surplus, yaitu desa yang sistem produksinya berorientasi komersial, sehingga ekonomi masyarakat desa tersebut sangat tergantung pada dinamika pasar.

Penelitian ini menggunakan pendekatan studi kasus, karena penelitian hanya dilakukan pada beberapa lokasi yang merupakan representasi dari wilayah yang memiliki sumber daya perikanan perairan umum daratan dengan ekosistem danau, waduk, sungai, dan sungai rawa. Pada setiap lokasi penelitian dilakukan survey untuk mengumpulkan data variabel sosial ekonomi pada setiap aspek-aspek generik minapolitan. Pengumpulan data variabel sosial ekonomi ini dipandu dengan daftar topik data dan daftar pertanyaan. Data tersebut dapat berupa data sekunder maupun data primer. Data dan informasi tersebut terkait dengan produksi, penyerapan tenaga kerja, pendapatan, dan industri-industri yang berkaitan untuk mendukung program minapolitan, yang secara keseluruhan mengemukakan kondisi aktivitas perekonomian yang berlangsung pada kawasan minapolitan.

Data primer dikumpulkan dan diperoleh dari responden yang berada di desa atau kawasan tertentu yang menjadi pusat pertumbuhan kawasan minapolitan. Responden terkait dengan penelitian minapolitan berbasis sumber daya dan usaha perikanan perairan umum adalah masyarakat pemanfaat dan pengelola sumber daya dan usaha perikanan di wilayah perairan umum; 
dalam hal ini termasuk masyarakat nelayan, tokoh masyarakat, pejabat dan/atau petugas pemerintahan, informan kunci, pengusaha, dan responden perorangan yang terdapat pada suatu kawasan minapolitan yang ditetapkan dalam penelitian ini.

Data sekunder yang dikumpulkan antara lain berasal dari laporan hasil penelitian dan/atau kajian yang terkait dengan berbagai aspek yang merupakan dasar kajian model minapolitan. Kumpulan data tersebut diperlukan dalam rangka merumuskan model minapolitan berbasis sumber daya perikanan perairan umum daratan. Identifikasi keunggulan lokasi terkait dengan pengembangan kawasan minapolitan dilakukan dengan cara mengumpulkan dan menganalisis data yang terkait dengan jarak pasar, potensi sumber daya, prospek pertumbuhan ekonomi, infrastruktur dan lain-lain. Keunggulan tersebut kemudian dijadikan bahan untuk menyempurnakan model minapolitan pada kawasan yang diteliti. Di samping itu ditambahkan pula pertimbangan perkembangan aktivitas perekonomian pada kawasan minapolitan yang diteliti. Data ini dapat berupa data sekunder maupun data primer yang secara mendasar digali dari variabel sosial ekonomi pada setiap aspek generik model minapolitan.

\section{Teknik Pengumpulan Data}

Teknik pengumpulan data pada kegiatan penelitian ini dilakukan cara studi literatur, wawancara, Rapid Rural Appraisal (RRA) dan mail survey. Studi literatur merupakan kajian yang menitikberatkan pada analisis atau interpretasi bahan tertulis berdasarkan konteksnya. Hal ini dilakukan dengan cara penelusuran dokumen yang terkait dengan topik penelitian. Wawancara dilakukan dengan menggunakan panduan topik data (untuk data sekunder) dan daftar pertanyaan (untuk data primer). Rapid Rural Appraisal (RRA) merupakan metode cepat dalam memahami kondisi wilayah tertentu dikaitkan dengan keperluan topik penelitian tertentu (Townsley, 1996).
Dalam hal ini digunakan untuk memahami kondisi wilayah kawasan minapolitan. Mail survey adalah survei yang dilakukan menggunakan teknik surat-menyurat dengan menggunakan daftar pertanyaan tertutup.

\section{Metode Analisis Data}

Data yang terkait dengan kegiatan penelitian ini dianalisis secara deskriptif. Analisis terkait dengan penelitian minapolitan berbasis sumber daya dan usaha perikanan perairan umum dilakukan menggunakan prinsip fungsional dan prinsip kesatuan keruangan kawasan dan fungsi-fungsi kelembagaan yang membangun kawasan minapolitan.

Metode yang digunakan untuk penentuan sentra produksi perikanan perairan umum daratan sebagai lokasi prioritas kawasan minapolitan dilakukan dengan pentahapan kegiatan yang dimulai dengan identifikasi variabel sosial ekonomi. Pada tahap ini, identifikasi berbagai variabel sosial ekonomi yang dibedakan berdasarkan; aspek sumberdaya dan tata ruang, aspek masyarakat dan bisnis, aspek kelembagaan, aspek kebijakan dan governance, aspek infrastruktur, aspek teknologi dan aspek pemasaran hasil perikanan. Penentuan prioritas lokasi kemudian dilakukan dengan cara memberikan katagori kesiapan lokasi minapolitan berdasarkan nilai-nilai variabel sosial ekonomi yang didapatkan untuk masing-masing lokasi minapolitan. Kemudian, dilakukan identifikasi kekuatan dan kelemahan kawasan minapolitan, yang selanjutnya dilakukan analisis kekuatan dan kelemahan kawasan minapolitan berbasis sumberdaya perikanan perairan umum daratan menggunakan pendekatan analisis Strength, Weakness, Opportunities, Threaths (SWOT) (Rangkuti, 2000).

\section{INDEKS KESIAPAN PENGEMBANGAN KAWASAN MINAPOLITAN}

Model pengembangan kawasan minapolitan berbasis perairan umum daratan dapat dikelompokkan menjadi 3 (tiga) ekosistem yaitu waduk, danau, dan sungai/ 
rawa dan rawa. Indeks kesiapan masing masing ekosistem berdasarkan variabel sosial ekonomi yang dikelompokkan ke dalam 7 (tujuh) aspek minapolitan dikemukakan sebagai berikut:

\section{Indeks Kesiapan Ekosistem Waduk}

Indeks kesiapan ekosistem waduk untuk dikembangkan sebagai kawasan minapolitan didapatkan dari lokasi lokasi yang ada di Kab. Wonosobo, Kab. Grobogan, Kab. Wonogiri, Kab. Mojokerto, Kab. Cianjur, dan Kab. Purwakarta. Secara rata rata indeks kesiapan ekosistem waduk dapat dilihat pada Tabel 1.
Purwakarta, Cianjur, Wonogiri, dan Wonosobo (Gambar 1).

\section{Indeks Kesiapan Ekosistem Danau}

Indeks kesiapan ekosistem danau untuk dikembangkan sebagai kawasan minapolitan didapatkan dari lokasi lokasi yang ada di Kab. Gorontalo, Kota Cilegon, Kab. Bangka, Kota Pangkal Pinang, Kab. Bangli, Kab. Taliwang, Kota Jayapura, Kab. Solok, Kab. Kerinci, Kab. Agam, dan Kab. Simalungun. Secara rata rata indeks kesiapan ekosistem danau dapat dilihatpada Tabel 2.

Tabel 1. Indeks Kesiapan Lokasi Pengembangan Kawasan Minapolitan berdasarkan Aspek Generik Minapolitan pada Ekosistem Waduk, Tahun 2011.

Table 1. Area Development Location Readiness Index is Based on Aspects of Generic Minapolitan on Reservoir Ecosystems, 2011.

\begin{tabular}{clc}
\hline No & \multicolumn{1}{c}{$\begin{array}{c}\text { Aspek Generik Minapolitan } \\
\text { (Generic aspects of Minapolitan) }\end{array}$} & $\begin{array}{c}\text { Rata-Rata Nilai } \\
\text { (Average) }\end{array}$ \\
\hline 1. & Infrastruktur /Infrastructure & 52,38 \\
2. & Masyarakat dan Bisnis /Community and Business & 68,69 \\
3. & Sumber daya dan Tata ruang /Resources and the spatial & 42,17 \\
4. & Kelembagaan /Institutional & 56,76 \\
5. & Teknologi /Technology & 46,03 \\
6. & Kebijakan dan Tata Kelola Pemerintah /Policy and Governance & 34,94 \\
7. & Pemasaran hasil perikanan /Marketing of fishery & 57,44 \\
& Rata-rata /Average & $\mathbf{5 1 , 2 0}$ \\
\hline
\end{tabular}

Sumber: Data primer, diolah. 2011/ Sources: Primary data, processed. 2011

Tabel 1 memperlihatkan bahwa berdasarkan ke tujuh aspek minapolitan, terlihat bahwa ekosistem perairan umum waduk tergolong sebagai lokasi yang maju $(51,20)$, meskipun nilainya lebih mendekati ke nilai pemula (50). Dapat diketahui juga bahwa aspek yang paling rendah nilainya adalah aspek kebijakan dan tata kelola pemerintah dalam kaitannya dengan pengembangan kawasan waduk sebagai wilayah pembangunan dan pengembangan perikanan. Dari keseluruhan lokasi ekosistem ini, terlihat pula bahwa lokasi yang maju terdapat di Kabupaten
Pada Tabel 2 terlihat bahwa pada ekosistem danau, nilai yang paling rendah terdapat pada aspek sumberdaya dan tata ruang. Di samping itu, pada ekosistem danau ini terlihat aspek masyarakat dan bisnis merupakan aspek yang paling mendukung pengembangan minapolitan. Kemudian, secara keseluruhan lokasi ekosistem danau ini tergolong kesiapannya sebagai lokasi yang maju dengan indeks kesiapan 56,59. Dari keseluruhan lokasi ekosistem ini, terlihat pula bahwa lokasi yang maju terdapat Kab. Bangka, Kota Pangkal Pinang, Kab. Bangli, Kab. Agam, Kota Jayapura, Kab. Solok, dan Kab. Taliwang (Gambar 2). 


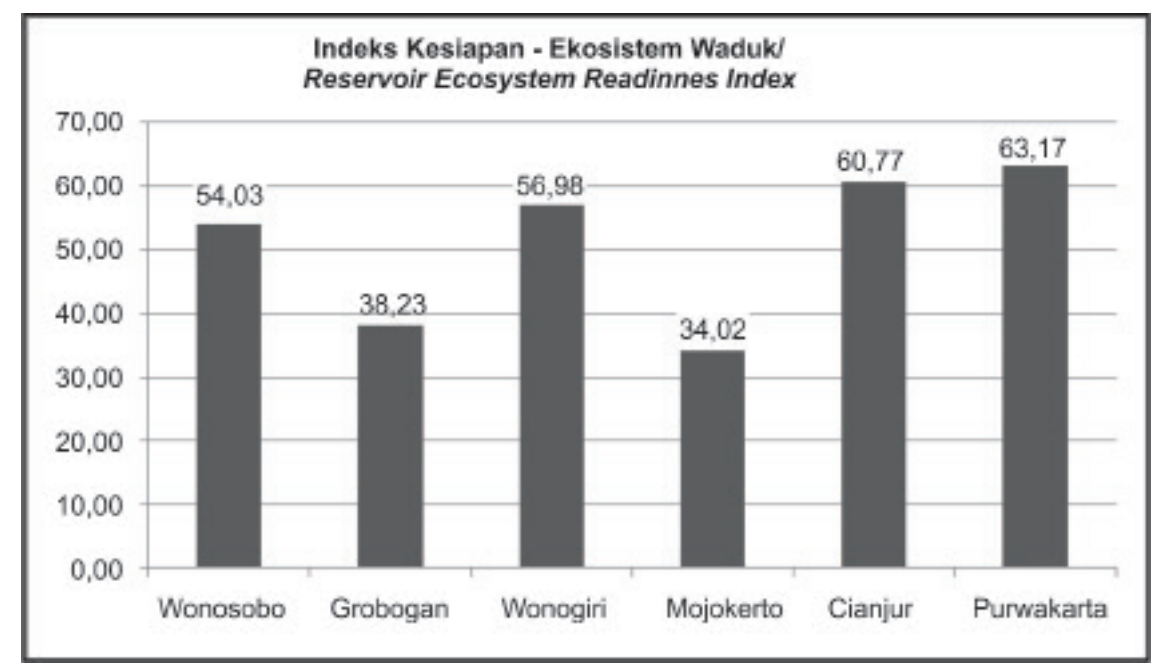

Sumber: Data primer, diolah. 2011/ Sources: Primary data, processed. 2011

\section{Gambar 1. Indeks Kesiapan Lokasi Pengembangan Kawasan Minapolitan Berbasis Ekosistem Waduk di Indonesia, Tahun 2011. \\ Figure 1. Area Development Location Readiness Index is Based on Reservoir Ecosystems in Indonesia, 2011.}

Tabel 2. Indeks Kesiapan Lokasi Pengembangan Kawasan Minapolitan berdasarkan Aspek Generik Minapolitan pada Ekosistem Danau, Tahun 2011.

Table 2. Area Development Location Readiness Index is Based on aspects of Generic Minapolitan on Lake Ecosystems, 2011.

\begin{tabular}{clc} 
No. & \multicolumn{1}{c}{$\begin{array}{c}\text { Aspek Generik Minapolitan/ } \\
\text { Generic Aspects of Minapolitan }\end{array}$} & $\begin{array}{c}\text { Rata-Rata Nilai } \\
\text { (Average) }\end{array}$ \\
\hline 1. & Infrastruktur/Infrastructure & 52,10 \\
2. & Masyarakat dan Bisnis /Community and Business & 74,53 \\
3. & Sumber daya dan Tata ruang /Resources and the spatial & 37,30 \\
4. & Kelembagaan/Institutional & 65,50 \\
5. & Teknologi/Technology & 52,38 \\
6. & Kebijakan dan Tata Kelola Pemerintah/Policy and Governance & 57,28 \\
7. & Pemasaran hasil perikanan /Marketing of fishery & 57,03 \\
& Rata-rata /Average & $\mathbf{5 6 , 5 9}$ \\
\hline
\end{tabular}

Sumber: Data primer, diolah. 2011/ Sources: Primary data, processed. 2011

Indeks Kesiapan Ekosistem Sungai/Rawa dan Rawa

Indeks kesiapan ekosistem sungai rawa dan rawa untuk dikembangkan sebagai kawasan minapolitan didapatkan dari lokasi yang terdapat di 27 kabupaten kota seperti yang ada pada Gambar 3.
Secara rata rata indeks kesiapan ekosistem sungai/rawa dan rawa dapat dilihat pada Gambar 3. Gambar 3 memperlihatkan bahwa lokasi minapolitan dengan ekosistem sungai/rawa dan rawa kesiapannya tergolong maju $(53,81)$, namun memiliki nilai yang rendah pada aspek sumberdaya dan tata ruang. 


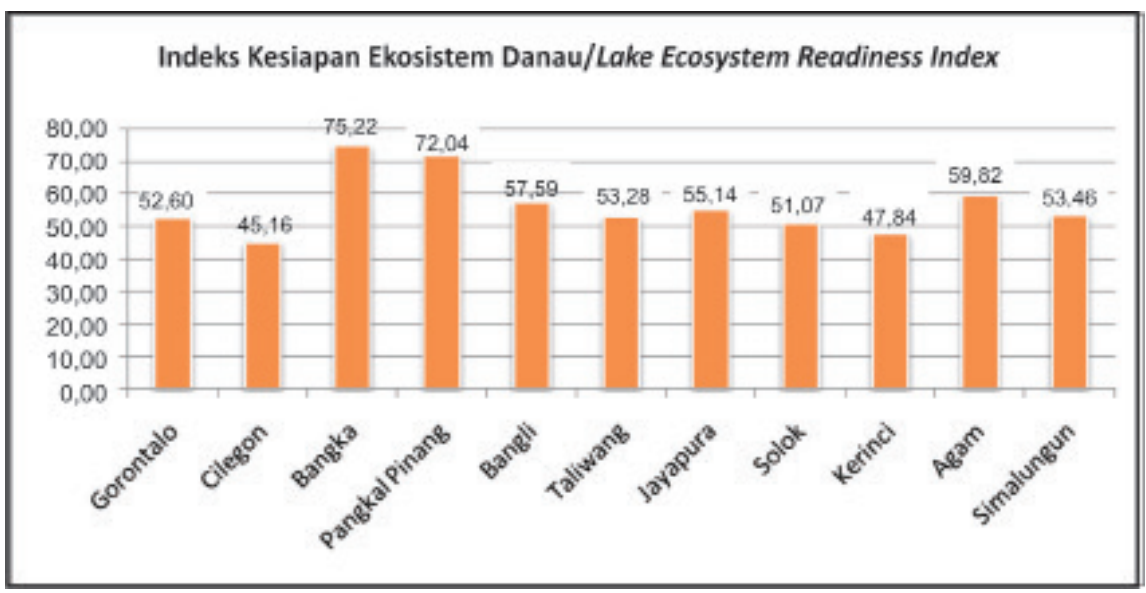

Sumber: Data primer, diolah. 2011/ Sources: Primary data, processed. 2011

Gambar 2. Indeks Kesiapan Lokasi Pengembangan Kawasan Minapolitan Berbasis Ekosistem Danau di Indonesia, Tahun 2011.

Figure 2. Area Development Location Readiness Index is Based on Lake Ecosystems in Indonesia, 2011.

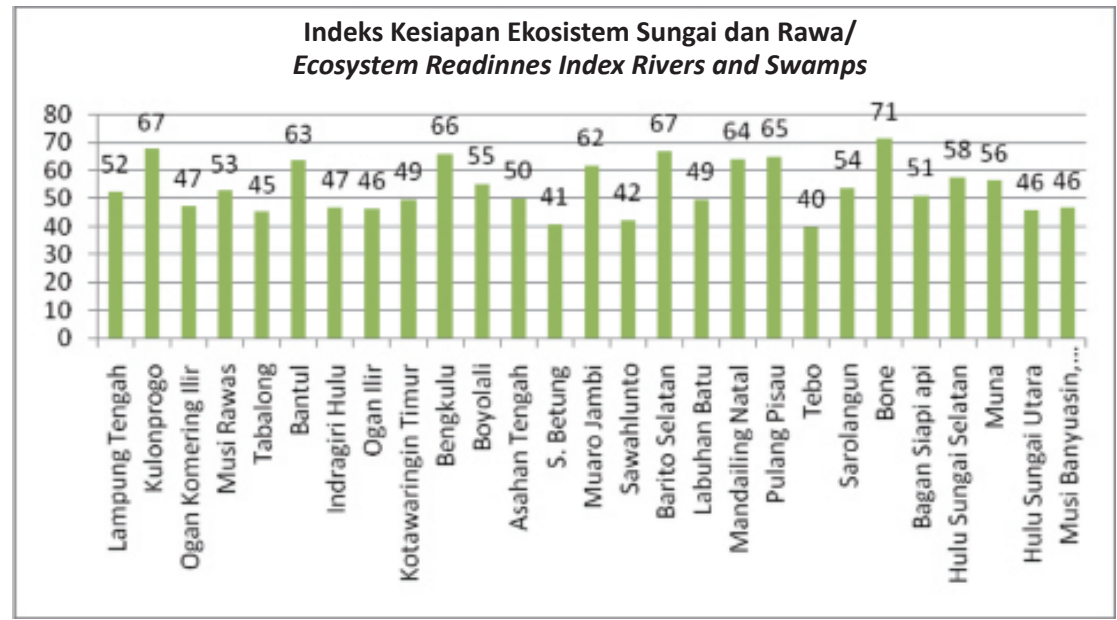

Sumber: Data primer, diolah. 2011/ Sources: Primary data, processed. 2011

Gambar 3. Indeks Kesiapan Lokasi Pengembangan Kawasan Minapolitan Berbasis Ekosistem Sungai dan Rawa di Indonesia, Tahun 2011.

Figure 3. Area Development Location Readiness Index is Based on Ecosystem River and Swamps in Indonesia, 2011.

Dari keseluruhan lokasi ekosistem ini, terlihat pula bahwa lokasi yang maju terdapat Kabupaten Bone, Kabupaten Barito Selatan, Kulonprogo, Bantul, Bengkulu, Mandailing Natal, Pulang Pisau, Muaro Jambi, Hulu Sungai Selatan, dan Lampung Tengah.

\section{STRATEGI PENGEMBANGAN KAWASAN MINAPOLITAN}

Strategi pengembangan kawasan minapolitan yang dikemukakan dianalisis berdasarkan analisis SWOT yang dilakukan pada masing-masing lokasi yang dikunjungi, namun tidak berdasarkan ekosistem dan 
indeks kesiapan lokasi pengembangan kawasan minapolitan. Hal ini didasarkan atas pertimbangan bahwa untuk ekosistem yang sama masih terdapat perbedaan tingkat perkembangan kemajuan dilihat dari segi pemanfaatan dan pengelolaannya.

Begitu pula untuk kelompok kesiapan yang sama masih terdapat perbedaan kesiapan jika dilihat terhadap 7 (tujuh) aspek yang menjadi ciri khusus lokasi minapolitan. Dengan demikian strategi pengembangan kawasan minapolitan berbasis perairan umum daratan bersifat spesifik lokasi.

Strategi pengembangan untuk masingmasing ekosistem dirumuskan berdasarkan kondisi aktual dari lokasi survei Waduk Jatiluhur di Kab. Purwakarta, Jawa Barat untuk ekosistem waduk, Kab. Ogan Ilir, Sumatera Selatan untuk ekosistem sungai/rawa, Kab. Barito Selatan, Kalimantan Tengah untuk ekosistem sungai, dan Danau Toba di Kab. Simalungun, Sumatera Utara untuk ekosistem danau.

Perumusan rekomendasi strategi pengembangan dilakukan dengan pendekatan analisis SWOT meliputi: (1) identifikasi isu aktual, (2) identifikasi faktor internal (kekuatan dan kelemahan) dan faktor eksternal (peluang dan ancaman), (3) komparasi masing-masing faktor internal dan faktor eksternal, (4) tabulasi antar faktor internal dan faktor eksternal, dan (5) penentuan kuadran, kemudian (6) dirumuskan strategi dan kebijakan dalam pengembangan kawasan minapolitan perairan umum.

\section{Tabel 4. Matriks Strategi Pengembangan Kawasan Minapolitan Perairan Umum Waduk Jatiluhur, Kabupaten Purwakarta, Jawa Barat, Tahun 2011.}

Table 4. Minapolitan Area Development Strategy of Jatiluhur, Purwakarta regency, West Java, 2011.

\begin{tabular}{|c|c|c|}
\hline $\begin{array}{l}\text { Faktor Internal } \\
\text { (Internal factors) }\end{array}$ & Kekuatan (Strength) & Kelemahan (Weakness) \\
\hline $\begin{array}{l}\text { Faktor Eksternal } \\
\text { (External factors) }\end{array}$ & Investasi PLTA (PLTA investment) & $\begin{array}{l}\text { Air waduk sangat rentan terhadap } \\
\text { perubahan iklim dan pengaruh } \\
\text { perubahan kualitas air hulu sungai } \\
\text { (Reservoirs are vulnerable to climate } \\
\text { change and the effects of changes in } \\
\text { river water quality) }\end{array}$ \\
\hline $\begin{array}{l}\text { Peluang (Opportunity) } \\
\text { Waduk Jatiluhur sebagai } \\
\text { sumber utama penggerak } \\
\text { PLTA, bahan baku air } \\
\text { minum, dan bahan baku } \\
\text { untuk industri di wilayah } \\
\text { Purwakarta dan DKI Jakarta } \\
\text { (Jatiluhur as the primary } \\
\text { source of PLTA, raw water, } \\
\text { and raw materials for } \\
\text { industries in the region } \\
\text { Purwakarta and Jakarta) }\end{array}$ & $\begin{array}{l}\text { Waduk Jatiluhur dengan fungsi } \\
\text { utama sebagai investasi PLTA } \\
\text { harus dijaga keutamaan fungsi } \\
\text { sebagai PLTA, bahan baku } \\
\text { air minum, dan bahan baku } \\
\text { air untuk industri di wilayah } \\
\text { Purwakarta dan DKI Jakarta } \\
\text { (Jatiluhur with the main function } \\
\text { as PLTA must be maintained as } \\
\text { a function of PLTA, raw water } \\
\text { and raw materials for industries } \\
\text { in the region Purwakarta and } \\
\text { Jakarta) }\end{array}$ & $\begin{array}{l}\text { Perlu menjaga kualitas air waduk dan } \\
\text { kualitas air pada bagian hulu sungai } \\
\text { agar tetap dapat dijadikan sebagai } \\
\text { sumber utama penggerak PLTA, bahan } \\
\text { baku air minum, dan bahan baku } \\
\text { untuk industri di wilayah Purwakarta } \\
\text { dan DKI Jakarta (Need to maintain } \\
\text { the water quality of reservoirs and } \\
\text { water quality upstream of the river } \\
\text { in order to continue to serve as PLTA, } \\
\text { raw water, and raw materials for } \\
\text { industries in the region Purwakarta } \\
\text { and Jakarta) }\end{array}$ \\
\hline $\begin{array}{l}\text { Sulitnya mengawasi } \\
\text { kesesuaian jumlah } \\
\text { KJA terhadap ijin yang } \\
\text { dikeluarkan (The difficulty } \\
\text { of supervise the KJA number } \\
\text { of licenses issued }\end{array}$ & $\begin{array}{l}\text { Waduk Jatiluhur merupakan } \\
\text { Investasi PLTA sehingga harus } \\
\text { dijaga keberlanjutannya } \\
\text { terutama dari ancaman } \\
\text { sulitnya mengawasi kesesuaian } \\
\text { jumlah KJA terhadap ijin yang } \\
\text { dikeluarkan (Jatiluhur must be } \\
\text { preserved from the threat of } \\
\text { sustainability particularly from } \\
\text { the difficulty of supervise the } \\
\text { KJA number of liceses issued) }\end{array}$ & $\begin{array}{l}\text { Perlu mempertahankan kualitas air } \\
\text { waduk dan kualitas air pada bagian } \\
\text { hulu sungai disamping melakukan } \\
\text { pengawasan terhadap kesesuaian } \\
\text { jumlah KJA terhadap ijin yang } \\
\text { dikeluarkan (Maintain the water } \\
\text { quality of reservoirs and water quality } \\
\text { upstream of the river in addition } \\
\text { to supervising the suitability of the } \\
\text { number of licenses issued of KJA) }\end{array}$ \\
\hline
\end{tabular}

Sumber: Data primer, diolah. 2011/ Sources: Primary data, processed. 2011 


\section{Strategi Pengembangan Minapolitan Ekosistem Waduk}

Pada Tabel 4 ditampilkan hasil analisis SWOT berdasarkan 7 (tujuh) aspek generik minapolitan pada ekosistem Waduk Jatiluhur yang ada di Kab. Purwakarta, Jawa Barat.

Berdasarkan Tabel 4, rumusan strategi utama yang dapat disampaikan dalam pengembangan kawasan minapolitan perairan umum waduk adalah:

1) Menjaga keberlanjutan keberadaan dan fungsi waduk terutama dari ancaman sulitnya mengawasi kesesuaian jumlah KJA terhadap ijin yang dikeluarkan. Hal ini penting karena waduk fungsi utamanya adalah sebagai sumber utama penggerak PLTA yang merupakan investasi negara, di samping juga sebagai sumber bahan baku air minum, dan bahan baku untuk industri lokal (tingkat kabupaten) maupun regional (antar propinsi dan atau antar kabupaten).

2) Pengembangan perikanan, terutama perikanan budidaya KJA sangat perlu dibatasi sesuai dengan ketetapan daya dukung perairan tersebut dan sesuai pula dengan peruntukan tata ruang yang telah ditetapkan pada perairan waduk.

\section{Strategi Pengembangan Minapolitan Ekosistem Sungai/Rawa}

Pada Tabel 5 ditampilkan hasil analisis SWOT berdasarkan 7 (tujuh) aspek generik minapolitan pada ekosistem sungai/ rawa yang ada di Kab. Ogan Ilir, Sumatera Selatan.

Tabel 5. Matrik Strategi Pengembangan Kawasan Minapolitan Perairan Umum Sungai/Rawa di Kabupaten Ogan Ilir, Sumatera Selatan, Tahun 2011.

Table 5. Minapolitan Area Development Strategy of the River/Swamps in Ogan Ilir Regency, South Sumatra, 2011.

\begin{tabular}{|c|c|c|}
\hline $\begin{array}{l}\text { Faktor Internal } \\
\text { (Internal factors) }\end{array}$ & Kekuatan (Strength) & Kelemahan (Weakness) \\
\hline $\begin{array}{l}\text { Faktor Eksternal } \\
\text { (External factors) }\end{array}$ & $\begin{array}{l}\text { Sumber daya air selalu tersedia sepanjang } \\
\text { tahun terutama di bagian sungai utama (Water } \\
\text { resources are always available throughout the } \\
\text { year especially in the main river) }\end{array}$ & $\begin{array}{l}\text { Sumber-sumber produktivitas ikan } \\
\text { yang tinggi tetap dilelang oleh Pemda } \\
\text { (The sources of the high productivity } \\
\text { of fish remains auctioned by the } \\
\text { government) }\end{array}$ \\
\hline $\begin{array}{l}\text { Peluang (Opportunity) } \\
\text { Tingginya harga ikan hasil } \\
\text { tangkapan (The high price } \\
\text { of the fish) }\end{array}$ & $\begin{array}{l}\text { Manfaatkan sumber daya air yang selalu } \\
\text { tersedia sepanjang tahun terutama di bagian } \\
\text { sungai utama untuk kegiatan penangkapan ikan } \\
\text { dan jaga kualitas ikan hasil tangkapan agar tidak } \\
\text { terjadi penurunan harga ikan hasil tangkapan } \\
\text { (Take advantage of water resources are always } \\
\text { available throughout the year especially in the } \\
\text { main river for fishing activities and maintain } \\
\text { the quality of the fish in order to avoid price } \\
\text { reductions of fish. }\end{array}$ & $\begin{array}{l}\text { Perhatikan keberlangsungan } \\
\text { pemanfaatan sumber-sumber } \\
\text { produktivitas ikan yang tinggi yang } \\
\text { tetap dilelang karena tingginya } \\
\text { harga ikan hasil tangkapan (Note the } \\
\text { use of sustainable sources of fish } \\
\text { productivity remains of auctioned) }\end{array}$ \\
\hline $\begin{array}{l}\text { Terisolasinya desa- } \\
\text { desa perikanan dan } \\
\text { belum baiknya sarana } \\
\text { transportasi darat } \\
\text { (Isolation of the } \\
\text { villages and not good } \\
\text { transportation) }\end{array}$ & $\begin{array}{l}\text { Manfaatkan sumberdaya air yang selalu tersedia } \\
\text { sepanjang tahun terutama di } \\
\text { bagian sungai utama sebagai sarana transportasi } \\
\text { penghubung desa-desa perikanan yang terisolasi } \\
\text { sebelum adanya perbaikan sarana transportasi } \\
\text { darat (Take advantage of water resources are } \\
\text { always available throughout the year especially } \\
\text { in the main river as a means of transportation } \\
\text { connecting villages are isolated prior to the } \\
\text { improvement of transportation facilities }\end{array}$ & $\begin{array}{l}\text { Manfaatkan pendapatan yang } \\
\text { diperoleh Pemda dari hasil lelang } \\
\text { lokasi tangkapan ikan tinggi untuk } \\
\text { memperbaiki sarana transportasi } \\
\text { darat di desa-desa perikanan } \\
\text { yang terisolasi (Take advantage } \\
\text { of government revenue from the } \\
\text { auction for improve transportation } \\
\text { facilities in the villages are isolated }\end{array}$ \\
\hline
\end{tabular}

Sumber: Data primer, diolah. 2011/ Sources: Primary data, processed. 2011 
Berdasarkan Tabel 5, rumusan strategi utama yang dapat disampaikan dalam pengembangan kawasan minapolitan perairan umum sungai/rawa adalah:

1) Manfaatkan sumberdaya air yang selalu tersedia sepanjang tahun terutama di bagian sungai utama sebagai sarana transportasi penghubung desa-desa perikanan yang terisolasi sebelum adanya perbaikan sarana transportasi darat dan sebagai jalur pemasaran ikan hasil tangkapan.

2) Manfaatkan sumber daya air yang selalu tersedia sepanjang tahun terutama di bagian sungai utama untuk kegiatan penangkapan ikan, dengan tetap menjaga kelestarian usaha dan kualitas ikan hasil tangkapan agar tidak terjadi penurunan volume dan harga ikan hasil tangkapan. Untuk itu, perlu memanfaatkan pendapatan yang diperoleh Pemda dari hasil lelang lokasi tangkapan ikan untuk tujuan konservasi dan memperbaiki sarana transportasi darat di desa-desa perikanan yang terisolasi.

\section{Strategi Pengembangan Minapolitan Ekosistem Sungai}

Pada Tabel 6 ditampilkan hasil analisis SWOT berdasarkan 7 (tujuh) aspek generik minapolitan pada ekosistem sungai yang ada di Kab. Barito selatan, Kalimantan Tengah.

Tabel 6. Matrik Strategi Pengembangan Kawasan Minapolitan Perairan Umum Sungai di Kabupaten Barito Selatan, Kalimantan Tengah, Tahun 2011.

Table 6. Minapolitan Area Development Strategy of the River in District South Barito, Central Kalimantan, 2011.

\begin{tabular}{|c|c|c|}
\hline $\begin{array}{r}\text { Faktor Internal } \\
\text { (Internal Factors) }\end{array}$ & Kekuatan (Strength) & Kelemahan (Weakness) \\
\hline $\begin{array}{l}\text { Faktor Eksternal } \\
\text { (External Factors) }\end{array}$ & $\begin{array}{l}\text { Lokasi Barito Selatan Strategis untuk } \\
\text { pemasaran (Strategic Location of } \\
\text { South Barito for Marketing) }\end{array}$ & $\begin{array}{c}\text { Kualitas SDM rendah } \\
\text { (Low Quality of Human Resources) }\end{array}$ \\
\hline $\begin{array}{l}\text { Tingginya tingkat } \\
\text { permintaan hasil } \\
\text { perikanan (The high level } \\
\text { of demand for fishery) }\end{array}$ & $\begin{array}{l}\text { Pembangunan infrastruktur } \\
\text { pendukung untuk mendukung } \\
\text { pemasaran hasil produksi dalam } \\
\text { rangka memenuhi permintaan pasar } \\
\text { (Developing infrastructure to support } \\
\text { the marketing of products in order to } \\
\text { satisfy demand) }\end{array}$ & $\begin{array}{l}\text { Peningkatan pengetahuan SDM } \\
\text { terkait dengan peningkatan } \\
\text { produksi perikanan melalui } \\
\text { pelatihan teknis dan penyuluhan } \\
\text { perikanan (Increased knowledge of } \\
\text { human resources associated with } \\
\text { increased fish production through } \\
\text { technical training and fisheries } \\
\text { extension) }\end{array}$ \\
\hline $\begin{array}{l}\text { Lokasi produksi jauh dari } \\
\text { pasar (Production sites } \\
\text { away from the market) }\end{array}$ & $\begin{array}{l}\text { Pembangunan infrastruktur } \\
\text { pendukung dan penggunaan sarana } \\
\text { dan prasarana transportasi yang } \\
\text { baik untuk mempercepat pemasaran } \\
\text { hasil produksi perikanan (Developing } \\
\text { infrastructure and use of facilities and } \\
\text { good transportation to accelerate the } \\
\text { marketing of fishery products) }\end{array}$ & $\begin{array}{l}\text { Peningkatan kualitas SDM yang } \\
\text { berada jauh dari pusat kegiatan } \\
\text { sebaiknya melalui penyuluhan yang } \\
\text { dilakukan oleh penyuluh-penyuluh } \\
\text { langsung di tempat mereka tinggal } \\
\text { (Improving the quality of human } \\
\text { resources that are far away from } \\
\text { the center through outreach } \\
\text { activities should be conducted by } \\
\text { the extension-extension directly in } \\
\text { where they live) }\end{array}$ \\
\hline
\end{tabular}

Sumber: Data primer, diolah. 2011/ Sources: Primary data, processed. 2011 
Berdasarkan Tabel 6, rumusan strategi utama yang dapat disampaikan dalam pengembangan kawasan minapolitan perairan umum sungai adalah:

1) Membangun infrastruktur pendukung dan penggunaan sarana dan prasarana transportasi yang baik untuk mempercepat pemasaran hasil produksi perikanan. Hal ini perlu dilakukan karena lokasi produksi jauh dari pasar

2) Membangun infrastruktur pendukung untuk mendukung pemasaran hasil produksi dalam rangka memenuhi permintaan pasar yang tinggi karena lokasi Barito Selatan yang strategis untuk pemasaran.

3) Meningkatkan pengetahuan dan ketrampilan SDM terkait dengan peningkatan produksi perikanan melalui pelatihan teknis dan penyuluhan perikanan.

\section{Strategi Pengembangan Minapolitan Ekosistem Danau}

Pada Tabel 7 ditampilkan hasil analisis SWOT berdasarkan 7 (tujuh) aspek generik minapolitan pada ekosistem danau yang ada di Kab. Simalungun, Sumatera Utara.

Tabel 7. Matrik Strategi Pengembangan Kawasan Minapolitan Perairan Umum Danau Toba, Sumatera Utara, Tahun 2011.

Table 7. Minapolitan Area Development Strategy of Lake Toba, North Sumatra,2011.

\begin{tabular}{|c|c|c|}
\hline $\begin{array}{r}\text { Faktor Internal } \\
\text { (Internal Factors) }\end{array}$ & Kekuatan (Strength) & Kelemahan (Weakness) \\
\hline $\begin{array}{l}\text { Faktor Eksternal } \\
\text { (External Factors) }\end{array}$ & $\begin{array}{l}\text { Tingkat Reproduksi Ikan Bilih } \\
\text { yang tinggi (Reproduction } \\
\text { Rates of Fish of Bilih is High) }\end{array}$ & $\begin{array}{l}\text { Banyaknya penggunaan alat } \\
\text { tangkap yang tidak ramah } \\
\text { lingkungan (The Number of } \\
\text { Fishing Gears That Are Not } \\
\text { Environmentally Friendly) }\end{array}$ \\
\hline $\begin{array}{l}\text { Tingginya tingkat } \\
\text { permintaan terhadap ikan } \\
\text { (The high level of demand } \\
\text { of fish) }\end{array}$ & $\begin{array}{l}\text { Pembentukan Balai Benih } \\
\text { Ikan untuk memfasilitasi } \\
\text { pembenihan ikan bilih } \\
\text { (Developing of Fish Seed } \\
\text { Center to facilitate fish } \\
\text { hatcheries of Bilih) }\end{array}$ & $\begin{array}{l}\text { Perbanyak penggunaan alat } \\
\text { tangkap yang lebih ramah } \\
\text { lingkungan untuk memenuhi } \\
\text { permintaan pasar terhadap ikan } \\
\text { (Expand the use of fishing gear } \\
\text { that is more environmentally } \\
\text { friendly way to satisfy the } \\
\text { market demand for fish) }\end{array}$ \\
\hline $\begin{array}{l}\text { Tidak adanya pembagian } \\
\text { wewenang pengelolaan } \\
\text { Danau Toba antara } \\
7 \text { kabupaten keliling } \\
\text { Danau Toba (The lack } \\
\text { of management of the } \\
\text { division of authority } \\
\text { between the } 7 \text { counties of } \\
\text { Lake Toba around) }\end{array}$ & $\begin{array}{l}\text { Perumusan kebijakan } \\
\text { pengelolaan Danau Toba } \\
\text { sehingga tingginya tingkat } \\
\text { reproduksi ikan Bilih dapat } \\
\text { dimanfaatkan (Lake Toba } \\
\text { management policy so that } \\
\text { the high rate of reproduction } \\
\text { of Bilih can be exploited) }\end{array}$ & $\begin{array}{l}\text { Perumusan kebijakan berkaitan } \\
\text { pembagian wewenang } \\
\text { pengelolaan Danau Toba dan } \\
\text { penggunaan alat tangkap di } \\
\text { tingkat Provinsi (Formulation of } \\
\text { policies relating to the division } \\
\text { of management authority Lake } \\
\text { Toba and the use of fishing gear } \\
\text { in the Province level) }\end{array}$ \\
\hline
\end{tabular}


Berdasarkan Tabel 7, rumusan strategi utama yang dapat disampaikan dalam pengembangan kawasan minapolitan perairan umum danau adalah:

1) Perumusan kebijakan berkaitan dengan pembagian tugas dan wewenang pengelolaan danau, sejalan dengan pembentukan Balai Benih Ikan untuk memfasilitasi pembenihan ikan dalam rangka pengembangan perikanan tangkap berbasis budidaya (Culture Based Fishery/ $C B F)$. Hal ini penting dilakukan karena secara geografis Danau Toba meliputi 7 (tujuh) wilayah kabupaten di Sumatera Utara.

2) Perumusan kebijakan penggunaan alat tangkap ramah lingkungan dan pengawasan/pengendalian penggunaannya di tingkat lapangan.

\section{KESIMPULAN DAN REKOMENDASI KEBIJAKAN}

Berdasarkan hasil penilaian terhadap aspek generik minapolitan, nilai indeks kesiapan yang paling rendah pada ekosistem waduk terdapat pada aspek kebijakan dan tata kelola pemerintahan. Sementara pada ekosistem danau, sungai/rawa dan rawa, nilai indeks kesiapan paling rendah terdapat pada aspek sumberdaya dan tata ruang. Dengan demikian, pengembangan kawasan minapolitan perairan umum daratan berdasarkan aspek generiknya terdapat perbedaan antar ekosistem meskipun tingkat kesiapannya sama sama tergolong maju. Implikasinya adalah strategi pengembangan kawasan minapolitan perairan umum daratan perlu memperhatikan jenis ekosistem, di samping aspek generik minapolitan. Hal ini sejalan dengan analisis SWOT yang menunjukkan bahwa strategi pengembangan kawasan minapolitan pada masing-masing ekosistem juga berbeda, sehingga berimplikasi pada langkah operasionalnya yang juga berbeda satu sama lain.

Strategi pengembangan ekosistem Waduk Jatiluhur menunjukkan bahwa kualitas air waduk perlu dijaga dengan baik dalam kaitan dan fungsinya sebagai tenaga penggerak penghasil listrik, sumber air baku air minum, dan sumber air baku untuk keperluan industri. Implikasinya, pengembangan perikanan terutama perikanan budidaya harus sesuai dengan tata ruang dan kapasitas dukungnya. Bahkan pengembangan lokasi waduk yang melebihi kapasitas dukungnya sudah terbukti di Waduk Saguling yang memiliki dampak kematian ikan secara masal pada periode yang singkat akibat buruknya kualitas lingkungan perairan waduk.

Pada lokasi ekosistem sungai dan rawa di Kabupaten Ogan Ilir dan Barito Selatan lebih difokuskan bagaimana sarana transportasi dapat dibangun, sehingga pemasaran ikan hasil produksi masyarakat nelayan atau pembudidaya dapat dipasarkan dalam kualitas yang baik. Dengan demikian, produktivitas perairan sungai dan rawa/sungai yang tinggi dapat dimanfaatkan hasilnya oleh masyarakat nelayan. Hal ini tentunya diiringi dengan pola pengelolaan yang dibangun oleh masyarakat nelayan, sehingga mereka dapat mengetahui dan memahami pentingnya pengelolaan sumberdaya perairan dan perikanan dalam mendukung keberlanjutan usaha mereka, yang pada gilirannya akan mentaatinya secara bersama.

Lokasi Danau Toba, lebih memerlukan perhatian dalam kaitannya dengan pengelolaan danau secara bersama diantara para pemangku kepentingan di kabupaten yang wilayah administrasinya juga meliputi kawasan Danau Toba. Melalui pengelolaan secara bersama, usaha penangkapan ikan bilih yang relatif melimpah dan sangat banyak permintaan pasarnya dapat dikelola secara terpadu dan dimanfaatkan secara berkelanjutan. Pengaturan penangkapan ikan menggunakan alat tangkap yang ramah lingkungan perlu ditetapkan pada seluruh wilayah kabupaten yang ada di kawasan danau. Begitu pula sistem pengawasannya perlu dibentuk dan ditegakkan, yang pada akhirnya berimplikasi pada upaya peningkatan kesejahteraan masyarakat nelayan. Di lain pihak, pengembangan KJA harus dibatasi sesuai dengan kapasitas dukung danau pada 
setiap wilayah kabupaten yang ada di wilayah keliling danau tersebut.

\section{PENUTUP}

Strategi pengembangan kawasan perairan umum daratan bersifat spesifik ekosistem karena dipengaruhi kesiapan faktor faktor sosial ekonomi sebagai lingkungan strategis yang member kekuatan dan kelemahan maupun peluang dan ancaman. Dari segi kesiapan sebagai kawasan pengembangan minapolitan, ada kesamaan "relatif" pada aspek terendah tingkat kesiapannya yaitu aspek sumberdaya dan tata ruang. Hal ini disebabkan oleh tata kelola yang kurang mendukung kepada pelestarian sumberdaya perikanan yang dibuktikan dengan semakin kecilnya ukuran dan volume ikan hasil tangkapan serta berkurangnya jenis ikan.

\section{DAFTAR PUSTAKA}

Adrianto, L. 2011. Konstruksi Lokal Pengelolaan Sumberdaya Perikanan di Indonesia. PT. Penerbit IPB Press. Bogor.

Hartoto, D.I. 2009. Peran Pengembangan Sistem Reservat dalam Pengelolaan Berkelanjutan Sumberdaya Perikanan Perairan Umum Daratan. (http://elib.pdii.lipi.go.id/katalog/ index.php/searchkatalog/byld/2872+per an+pengembangan+sistem+reservat+dal am+pengelolaan $\& \mathrm{~cd}=2 \& \mathrm{hl}=\mathrm{id} \& \mathrm{ct}=\mathrm{clnk} \&$ gl=id, diakses tanggal 29 Februari 2012).
Kartamihardja, E.S, K.Purnomo, D.W.H. Tjahjo, C. Umar, M.T.J. Sunarno dan S. Koeshendrajana. 2008. Petunjuk Teknis Pemulihan Sumberdaya Ikan di Perairan Umum Daratan Indonesia. Pusat Riset perikanan Tangkap. Badan Riset Kelautan dan Perikanan. Departemen Kelautan dan Perikanan. Jakarta.

Rangkuti, F. 2000. Analisis SWOT, Teknik Membedah Kasus Bisnis : Reorientasi Konsep Perencanaan Strategis untuk Menghadapi Abad 21. PT. Gramedia Pustaka Utama. Jakarta.

Townsley. 1996. Rapid Rural Appraisal Participatory Rural Appraisal, Participatory Rural Appraisal and Aquaculture. FAO. Rome

Zulham, A dan A.H. Purnomo. 2010. Minapolitan: Dari Konsep Menuju Implementasi. Balai Besar Riset Sosial Ekonomi Kelautan dan Perikanan. Badan Penelitian dan Pengembangan Kelautan dan Perikanan. Kementerian Kelautan dan Perikanan. Kementerian Kelautan dan Perikanan. Jakarta. 